\title{
CORRESPONDENCE
}

\section{Receptor-binding specificity of pandemic influenza A (H1N1) 2009 virus determined by carbohydrate microarray}

\begin{abstract}
To the Editor:
Since it first emerged in North America in mid-February 2009, the novel influenza A (H1N1) virus has spread to most other regions of the world, causing the World Health Organization (Geneva) to declare an emergent pandemic ${ }^{1}$. H1N1 is a reassortant virus with six of its eight genes, including the hemagglutinin (HA) gene, originating from "North American triple reassortant" swine H1 viruses ${ }^{2}$. Although these swine viruses have caused sporadic human infection in recent years, onward human-to-human transmission of infection was limited ${ }^{3}$. In relation to the increased transmissibility of the novel 'swine' virus and its establishment in the human population, the receptor specificity of the HA is a key determinant. The receptors are sialyl glycans, which vary in distribution in tissues of different species and determine host range and tissue tropism, as well as the capacity of animal viruses to initiate a human pandemic ${ }^{4}$.

In the June issue, Soundararajan et al. ${ }^{5}$ made a prediction concerning the receptor-binding specificity of a representative pandemic $\mathrm{H} 1 \mathrm{~N} 1$ 2009 virus, A/California/4/2009 (Cal/09).
\end{abstract}

The authors took account of the differences in amino acid residues in the receptorbinding site of $\mathrm{Cal} / 09$ from those of previous human H1N1 HAs and constructed homology-based HA-glycan structural complexes with 'human-type' oligosaccharide receptors, namely sialyl oligosaccharides terminating with $N$-acetylneuraminic acid $\alpha 2-6$-linked to galactose (Neu5Aco2-6Gal), and 'avian-type' terminating with Neu5Aco2$3 \mathrm{Gal}$. From these models, Soundararajan et al. predicted that $\mathrm{Cal} / 09$ would be able to make optimal contacts with $\alpha 2-6$-linked sialyl glycans, a feature shared with other human
H1N1 HAs and, in addition, make contacts with $\alpha 2$-3-linked sialyl glycans. However, features governing the receptor specificity of $\mathrm{HA}$ are complex and it is not always possible at present to draw definitive conclusions merely from sequence analysis and homology modeling studies.

We have compared directly, by carbohydrate microarray analysis, the receptor-binding characteristics of two isolates of the novel pandemic $\mathrm{H} 1 \mathrm{~N} 1$ virus, $\mathrm{Cal} / 09$ and $\mathrm{A} / \mathrm{Hamburg} / 5 / 2009$ (Ham/09), with those of a seasonal human H1N1 virus, A/Memphis/14/96-M (Mem/96), as representative of a virus well adapted to humans ${ }^{6}$. As the HA of the novel H1N1 pandemic virus originated from a virus similar to triple reassortant swine $\mathrm{H} 1 \mathrm{~N} 1$ viruses, we compared one such example, A/Iowa/1/2006 (Iowa/06), isolated from a human infection ${ }^{3}$, and an older close relative of classical swine $\mathrm{H} 1 \mathrm{~N} 1$ viruses, $\mathrm{A} / \mathrm{New}$ Jersey/76 (NJ/76), the human isolate that initiated the concern of a pandemic threat in 1976 (ref. 7). Information on the viruses and their analyses is provided in Supplementary Methods.

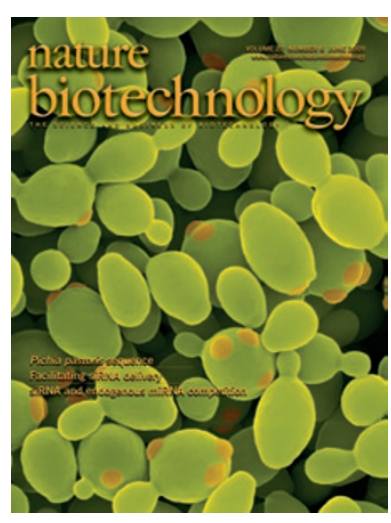

Our analysis system ${ }^{8,9}$ is based on the neoglycolipid (NGL) technology, which has been validated as an effective approach for presenting oligosaccharides for carbohydrate ligand assignments, not only for soluble carbohydratebinding proteins but also for whole cells, bacteria ${ }^{10}$ and virus-like particles ${ }^{11}$ that express carbohydratebinding proteins, many of which have low affinities. The special advantages of the lipid-linked probes noncovalently presented on a nitrocellulose matrix are their clustered state and an element of mobility that confer high avidity. Eighty- six sequence-defined oligosaccharide probes were incorporated (Supplementary Methods and Supplementary Table 1). These included eighty sialyl-terminating oligosaccharide probes with differing backbone types, chain lengths and branching patterns, also various sialylation, fucosylation and sulfation patterns, representative of $\mathrm{N}$ - and $\mathrm{O}$-glycans and glycolipids. Six neutral probes served as negative controls.

We observed a clear distinction between the receptor-binding repertoire of the pandemic $\mathrm{H} 1 \mathrm{~N} 1$ viruses $\mathrm{Cal} / 09$ and $\mathrm{Ham} / 09$ and that of the seasonal virus Mem/96 (Fig. 1). The $\mathrm{Cal} / 09$ and Ham/09 viruses bound not only to the majority of $\alpha 2-6$-linked sialyl sequences included irrespective of the backbone chain length and type, but also to a considerable range of $\alpha 2$-3-linked sialyl sequences. In contrast, Mem/96 bound exclusively to $\alpha 2-6$ linked sialyl sequences, and the binding was almost always to those with tetrasaccharide or longer backbones irrespective of the backbone type (type 1, Galß1-3GlcNAc or type 2, Galß1-4GlcNAc; Supplementary Table 1 and Supplementary Fig. 1). Even at a high virus concentration, no binding to the $\alpha 2$-3-linked sialyl sequences was observed (Supplementary Fig. 2). Features of the differential binding between the pandemic $\mathrm{H} 1 \mathrm{~N} 1$ viruses and the seasonal $\mathrm{H} 1 \mathrm{~N} 1$ virus Mem/96 are highlighted in Table 1 with selected probes that have closely related backbone sequences.

Although overall, the strongest binding of the H1N1 pandemic viruses was to $\alpha 2-6-$ linked sialyl sequences, binding of $\mathrm{Cal} / 09$ to some of the $\alpha 2$-3-linked sialyl sequences was comparable to that of the corresponding a2-6-linked sialyl probes, notably probes 18 and 20, based on disaccharide backbones, and 40, based on a branched hexasaccharidebackbone. Also in this relatively high binding category were sialyl Lewis ${ }^{\mathrm{x}}$-related probes 22 and 29, with di- and tetrasaccharide backbones, and the sulfated sialyl-Lewis ${ }^{\mathrm{x}}$ 
$\mathrm{Cal} / 09$

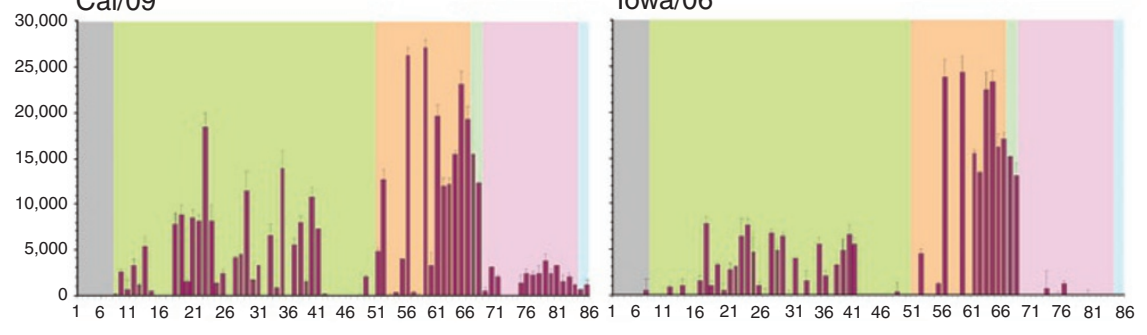

Ham/09

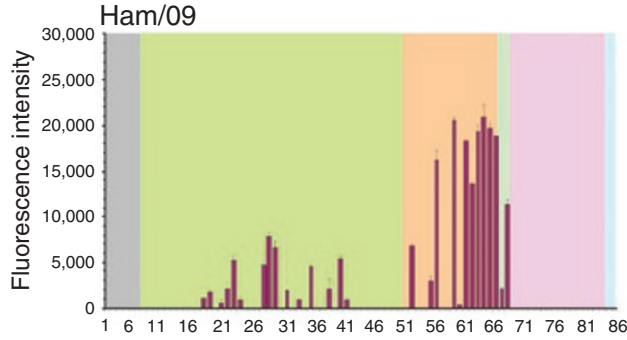

$\mathrm{NJ} / 76$

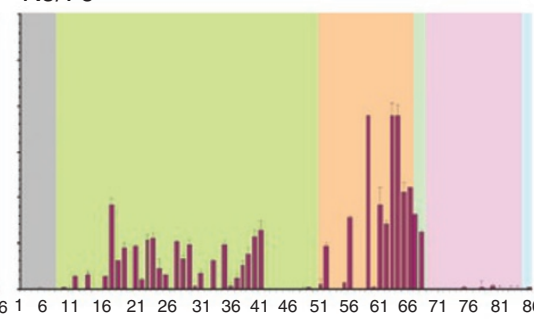

30,000 Mem/96

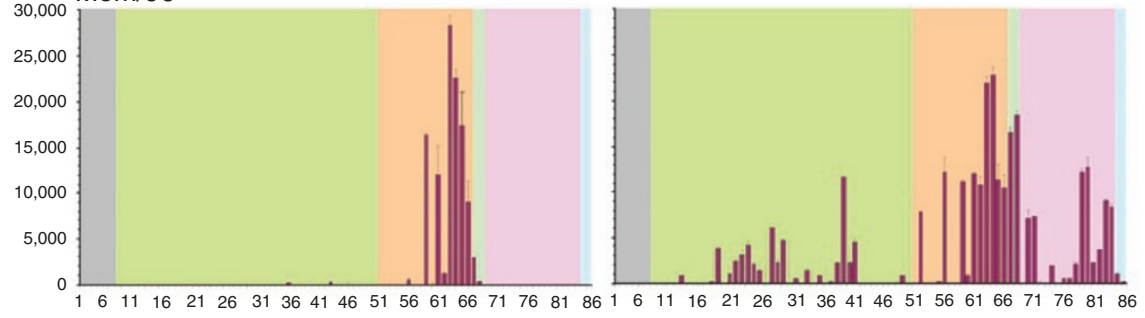

Oligosaccharide probes

$\square$ Neutral

$\square$ 2-3 Sialyl

2-6 Sialyl

2-3 \& 2-6 Sialyl

$\square$ 2-8 Sialyl

2-3 \& 2-8 Sialyl

Figure 1 Carbohydrate microarray analyses of the six viruses investigated. Numerical scores for the binding signals are shown as means of duplicate spots at $5 \mathrm{fmol}$ per spot (with error bars). The microarrays consisted of eighty sialylated and six neutral lipid-linked oligosaccharide probes, printed on nitrocellulose-coated glass slides. These are listed in Supplementary Table 1 and arranged according to sialic acid linkage, oligosaccharide backbone chain length and sequence. The various types of terminal sialic acid linkage are indicated by the colored panels as defined at the bottom of the figure.

probe 35 with sulfate on $N$-acetylglucosamine (Supplementary Table 1). Thus, our results using viruses are in accord with the prediction ${ }^{5}$ of dual specificity based on modeling of the HA protein of the Cal/09 virus. They contrast with those reported by Maines et al. ${ }^{12}$, who examined the binding of the soluble recombinant $\mathrm{HA}$ of $\mathrm{Cal} / 09$ to a limited set of biotinylated sialyl (poly) $N$-acetyllactosamine probes presented on immobilized streptavidin. Maines et al. detected binding to an $\alpha 2-6-$ linked sialyl sequence with tetrasaccharide backbone, but little or no binding to $\alpha 2$ 3 -linked sialyl probes with di-, tetra- or hexasaccharide backbones or to an $\alpha 2-6$ linked probe with a disaccharide backbone. As the affinities of individual HA molecules for their oligosaccharide receptors are low, multivalent interaction with receptors is necessary for high-avidity cooperative binding of virus. Thus, differences in clustering of the probes ${ }^{10}$ on the one hand, and of the HAs, presented on virus rather than as antibody complexes $^{12}$, on the other, are likely to account in part for the apparent higher avidity of binding in the present experiments.

Some differences between the two pandemic H1N1 isolates were, however, apparent in our analyses (Fig. 1, Table 1, Supplementary Table 1 and Supplementary Fig. 1). Cal/09 bound more strongly overall to $\alpha 2$-3-linked sialyl sequences and it bound to several short sequences (disaccharide backbones), for example, probes $8,10,12$ and 20, that are bound weakly by Ham/09. Moreover, $\mathrm{Cal} / 09$ bound to $\alpha 2-8$-linked polysialyl sequences as found on brain ganglioside GD3 (probes 70/71) and at the outer arms of $N$-glycans of the neural cell adhesion molecule (N-CAM; probes 75-84). These differences were less apparent when lower concentrations of virus were used, whereupon binding was predominantly to $\alpha 2-6$-linked sialyl probes and only weak binding to the 2 2-3-linked probes 27-29 could be discerned (Supplementary Fig. 3). There are three amino acid differences between the HAs of Ham/09 and Cal/09-S83P, A197T and V321I—which may account, at least in part, for these differences in binding. Whereas the residues in $\mathrm{Cal} / 09$ are less common, the sequence of Ham/09 is representative of the consensus sequence for the majority of recently circulating $\mathrm{H} 1 \mathrm{~N} 1$ pandemic viruses.

The patterns of receptor binding of the pandemic H1N1viruses, Cal/09 and Ham/09, were similar overall to those observed for the triple-reassortant $\mathrm{H} 1 \mathrm{~N} 1$ virus Iowa/06 and the classical swine $\mathrm{H} 1 \mathrm{~N} 1$ virus NJ/76 (Fig. 1, Table 1, Supplementary Table 1 and Supplementary Fig. 1), except that binding to $\alpha 2$-3-linked 4-O-acetylated sialyl probes 15/16 was observed only with the latter two viruses. This form of sialic acid has been identified in a number of animal species and in trace amounts in humans. The binding pattern of $\mathrm{X} 31$, a reassortant virus containing the $\mathrm{HA}$ and neuraminidase (NA) of A/Aichi/2/68 (H3N2) from the 1968 pandemic, also showed similarities to those of the two pandemic $\mathrm{H} 1 \mathrm{~N} 1$ isolates, with preferential binding to $\alpha 2-6$-linked and lower binding to the $\alpha 2-3$ linked sialyl sequences (Fig. 1, Table 1, Supplementary Table 1 and Supplementary Fig. 1). The pattern of binding to the $\alpha 2-3$ linked sequences was more reminiscent of Ham/09, whereas the binding to $\alpha 2$-8-linked sequences resembled $\mathrm{Cal} / 09$, but was more apparent even at low concentrations of virus (Supplementary Fig. 4).

These results indicate that no major change in receptor-binding specificity of the HA was required for the emergent pandemic virus to acquire human-like characteristics and become established in the human population. Other factors are likely to have contributed to the sustained human-to-human transmission of the pandemic $\mathrm{H} 1 \mathrm{~N} 1$ viruses in contrast to the sporadic infections by swine viruses. For example, acquisition of a novel NA by genetic reassortment ${ }^{2}$ may have provided better complementarity between the functional characteristics of the HA and NA of the emergent virus ${ }^{13}$.

The broader specificity, namely, the ability to bind to $\alpha 2$-3- in addition to $\alpha 2$-6-linked receptors is also pertinent to the greater virulence of the pandemic virus than seasonal influenza viruses observed in animal models, and its capacity to cause severe and fatal disease in humans, despite the generally mild nature of most infections. Binding to $\alpha 2-3$ linked receptors is thought to be associated with the ability of influenza viruses to infect the lower respiratory tract where there is a greater proportion of $\alpha 2-3$ - relative to $\alpha 2-6$ linked sialyl glycans ${ }^{14}$, although long chain 
Table 1 Features of binding to selected sialyl sequences.

\begin{tabular}{|c|c|c|c|c|c|c|c|}
\hline \multirow[b]{2}{*}{ Probe $^{a}$} & \multirow[b]{2}{*}{ Sequence $^{b}$} & \multicolumn{6}{|c|}{ Fluorescence signal intensities } \\
\hline & & Cal/09 & Ham/09 & Mem/96 & lowa/06 & $\mathrm{NJ} / 76$ & X31 \\
\hline 12 & NeuAc $\alpha-3 G a l \beta-4 G I c-A O^{c}$ & 5,191 & $-d$ & - & 930 & 1,459 & 836 \\
\hline 16 & Neu4,5Aco-3Gal $\beta$-4GIc-AO & - & - & - & 7,710 & 9,029 & 74 \\
\hline 52 & NeuAc $\alpha-6$ Gal $\beta-4 G \mid c-A O$ & 12,226 & 6,575 & - & 4,483 & 4,649 & 7,908 \\
\hline 20 & NeuAco-3Galß-4GIcNAc-AO & 8,146 & 488 & - & 2,699 & 4,607 & 1,135 \\
\hline 56 & NeuAco-6Galß-4GIcNAc-AO & 25,526 & 15,831 & 525 & 23,715 & 7,732 & 12,274 \\
\hline 23 & NeuAc $\alpha-3 G a l \beta-3 G I c N A c \beta-3 G a l \beta-4 G \mid c-D H^{e}$ & 7,875 & 874 & - & 7,555 & 5,438 & 4,184 \\
\hline 59 & NeuAc $\alpha-6$ Gal $\beta-4 G I c N A c \beta-3 G a l \beta-4 G I c-D H$ & 26,365 & 20,149 & 16,197 & 24,226 & 18,452 & 11,177 \\
\hline 40 & $\begin{array}{c}\text { Gal } \beta-4 \text { GIcNAc } \beta-6 \\
\text { Fuc } \alpha-3 \quad \text { Gal } \beta-4 G \mid c-D H \\
\text { NeuAc } \alpha-3 \text { Galß-3GIcNAc } \beta-3\end{array}$ & 10,462 & 5,222 & - & 6,548 & 5,965 & 2,367 \\
\hline 65 & $\begin{array}{c}\text { Galß-4GlcNAc } \beta-6 \\
\text { Fuc } \alpha-3 \quad \text { Gal } \beta-4 G \mid c-D H \\
\text { NeuAc } \alpha-6 \text { Galß-3GIcNAcß-3 }\end{array}$ & 22,468 & 19,284 & 17,304 & 16,137 & 10,417 & 11,361 \\
\hline 41 & $\begin{array}{cc}\text { NeuAc } \alpha-3 G a l \beta-4 G I c N A c \beta-2 M a n \alpha-6 & \text { Fuc } \alpha-6 \\
\mid & \text { Man } \beta-4 G I c N A c \beta-4 G I c N A c-D H \\
\text { NeuAc } \alpha-3 G a l \beta-4 G I c N A c \beta-2 M a n \alpha-3 & \end{array}$ & 6,997 & 890 & - & 5,486 & 6,263 & 4,590 \\
\hline 66 & $\begin{aligned} \text { NeuAc } \alpha-6 \text { Gal } \beta-4 G I c N A c \beta-2 M a n \alpha-6 & \\
\mid & \text { Man } \beta-4 G I c N A c \beta-4 G I c N A c-D H \\
\text { I } & \\
\text { NeuAc } \alpha-6 \text { Gal } \beta-4 G I c N A c \beta-2 M a n \alpha-3 & \end{aligned}$ & 18,684 & 18,424 & 9,035 & 17,083 & 10,776 & 10,480 \\
\hline
\end{tabular}

$\alpha 2$-3-linked sialyl (poly- $N$-acetyllactosamine) sequences are present in ciliated bronchial epithelial cells in humans where they are the receptors for another human pathogen, Mycoplasma pneumoniae ${ }^{15,16}$. The differences in receptor binding between the 2009 pandemic and seasonal H1N1 viruses may therefore account, at least in part, for the higher virus replication and greater pathology reported in the lungs of ferrets, mice and nonhuman primates infected with pandemic viruses, than observed with contemporary seasonal viruses ${ }^{12,17,18}$.

Note: Supplementary information is available on the Nature Biotechnology website.

ACKNOWLEDGMENTS

We thank M.S. Stoll for the microarray data analysis, storage and presentation software, and C. Herbert for assistance in preparation and characterization of the oligosaccharides and lipid-linked probes. S. Baumgarte is acknowledged for the clinical specimen from which A/Hamburg/5/2009 was isolated. We are grateful to H.-D. Klenk for helpful discussions and critical reading of the manuscript. This work was supported by grants from Wellcome Trust (WT085572MF) to T.F., A.H. and M.M.; UK Medical Research Council (G0600512), Biotechnology and Biological Sciences Research Council (BB/G000735/1), NCI Alliance of Glycobiologists for Detection of Cancer and Cancer Risk (U01 CA128416), UK Research Councils' Basic Technology Initiative
Translational Grant (EP/G037604/1) to T.F; and the European Union FP6 projects FLUPATH and FLUINNATE to M.M.

A.H. and S.W. are supported by the UK Medical Research Council, and A.S.P. is a fellow of the Fundação para a Ciência e Tecnologia (SFRH/BPD/26515/2006, Portugal).

Robert A Childs ${ }^{1,7}$, Angelina S Palma ${ }^{1,5,7}$, Steve Wharton ${ }^{2}$, Tatyana Matrosovich ${ }^{3}$, Yan Liu ${ }^{1}$, Wengang Chai ${ }^{1}$, Maria A Campanero-Rhodes ${ }^{1,6}$, Yibing Zhang ${ }^{1}$, Markus Eickmann ${ }^{3}$, Makoto Kiso ${ }^{4}$, Alan Hay ${ }^{2}$, Mikhail Matrosovich ${ }^{3,8}$ \& Ten Feizi ${ }^{1,8}$

${ }^{1}$ The Glycosciences Laboratory, Faculty of Medicine, Imperial College London, Northwick Park and St. Mark's Campus, Harrow, Middlesex, UK. ${ }^{2}$ Division of Virology, MRC National Institute for Medical Research, Mill Hill, London, UK. ${ }^{3}$ Institute of Virology, Philipps University, Marburg, Germany. ${ }^{4}$ Department of Applied Bioorganic Chemistry, Faculty of Applied Biological Sciences, Gifu University, Gifu, Japan. ${ }^{5}$ On leave from REQUIMTE, Centro de Química Fina e Biotecnologia, Departamento de Química, Faculdade de Ciências e Tecnologia, Universidade Nova de Lisboa, Caparica, Portugal. ${ }^{6}$ Present address: Instituto de Qumica-Física "Rocasolano", CSIC, Serrano 119, 28006 Madrid, Spain. 7,8 These authors contributed equally to this work. e-mail:t.feizi@imperial.ac.ukor m.matrosovich@gmail.com
1. WHO. Weekly Epid. Rec. 84, 249-257 (2009).

2. Dawood, F.S. et al. N. Engl. J. Med. 360, 2605-2615 (2009).

3. Shinde, V. et al. N. Engl. J. Med. 360, 2616-2625 (2009).

4. Matrosovich, M.N., Gambaryan, A.S. \& Klenk, H.D. in Avian Influenza-Monograms in Virology, vol. 27 (eds. Klenk, H.D., Matrosovich, M.N. \& Stech, J.) 134-155 (Karger, Basel, Switzerland, 2008).

5. Soundararajan, V. et al. Nat. Biotechnol. 27, 510-513 (2009).

6. Matrosovich, M., Matrosovich, T., Carr, J., Roberts, N.A \& Klenk, H.D. J. Virol. 77, 8418-8425 (2003)

7. Gaydos, J.C., Top, F.H. Jr., Hodder, R.A. \& Russell, P.K. Emerg. Infect. Dis. 12, 23-28 (2006).

8. Fukui, S., Feizi, T., Galustian, C., Lawson, A.M. \& Chai, W. Nat. Biotechnol. 20, 1011-1017 (2002).

9. Palma, A.S. et al. J. Biol. Chem. 281, 5771-5779 (2006).

10. Feizi, T. \& Chai, W. Nat. Rev. Mol. Cell Biol. 5, 582-588 (2004).

11. Campanero-Rhodes, M.A. et al. J. Virol. 81, 12846 12858 (2007).

12. Maines, T.R. et al. Science 325, 484-487 (2009).

13. Uhlendorff, J., Matrosovich, T., Klenk, H.D. \& Matrosovich, M. Arch. Virol. 154, 945-957 (2009).

14. Shinya, K. et al. Nature 440, 435-436 (2006).

15. Loomes, L.M. et al. Nature 307, 560-563 (1984).

16. Loveless, R.W., Griffiths, S., Fryer, P.R., Blauth, C. \& Feizi, T. Infect. Immun. 60, 4015-4023 (1992).

17. Munster, V.J. et al. Science 325, 481-483 (2009).

18. Itoh, Y. et al. Nature advance online publication, doi:10.1038/nature08260 (13 July 2009).

19. Liu, Y. et al. Chem. Biol. 14, 847-859 (2007).

20. Chai, W., Stoll, M.S., Galustian, C., Lawson, A.M. \& Feizi, T. Methods Enzymol. 362, 160-195 (2003). Corrected after print 5 February 2010. 


\section{Preventing the misuse of gene synthesis}

\section{To the Editor:}

As representatives of two companiesGENEART and DNA2.0 - that together are responsible for a majority of the world's manufacture of synthetic genes, we feel compelled to respond to Nouri and Chyba's proposition for "proliferation-resistant biotechnology," as published in the March issue $^{1}$. Gene synthesis enables a new world of possibilities: in the development of biofuels to combat climate change, in drug development to combat both persistent and emerging diseases, in agriculture to engineer crops that are more nutritious and resilient, and in research to bring a deeper understanding of the inner workings of the cell and of life itself. Biosafety and biosecurity are of utmost importance to us; even a small breach in biosecurity could damage the reputation and stability of our companies and our mission to facilitate the research that will bring solutions to the critical problems of the twenty-first century. We have the greatest incentive to ensure that the genes we synthesize do no harm and that the practice of gene synthesis remains safe.

Nouri and Chyba envision "the diffusion of advanced synthesizers from a few centralized locations to an increasing number of facilities and perhaps even individual laboratories..." as a result of "new and innovative approaches and declining development costs." They suggest equipping such synthesizers with software to block the synthesis of potentially harmful gene sequences. We counter, however, that their strategy is an ineffective way to increase public safety for several reasons.

First, the cat is already out of the bag. Gene synthesis has been around for a quarter of a century, and scarcely a month goes by without a new protocol being published ${ }^{2}$. Using web-based design tools ${ }^{3}$ and PCR-based protocols $^{4,5}$, gene synthesis can already be practiced in any lab, or even a startup garage if time and money are no object. Anyone who is sufficiently motivated could synthesize the gene for a toxin or even an entire viral genome ${ }^{6}$ using readily available reagents and without ever going near a specialized synthesizer.

Second, there are often legitimate reasons in the interest of safeguarding human populations for synthesizing genes that encode parts of toxins and harmful viruses, for example, as therapeutics ${ }^{7}$ or as sources of antigens. Synthesis of these genes would require protocols for bypassing the dangeroussequence block on the synthesizers, further increasing the ease with which hackers could evade these controls. Nouri and Chyba do acknowledge the need for certain scientists and laboratories to have access to select agents, and they recommend that a special software patch would be granted to those that have clearance. Whatever solution is used to bypass the block thus creates a vulnerability that would most certainly be exploited by terrorists or organizations serious about causing destruction.

Third, gene synthesis appears to be an unlikely tool for anyone seriously considering harm. Why would a nefarious agent bother with the expense and expertise required for synthesis when it would be much easier to find Bacillus anthracis in any pasture land? Why would a terrorist risk the exposure of attempting to order a dangerous sequence from a synthesis company-which would still require significant laboratory expertise to transform into a viable agent-when so many other conventional methods for causing harm are readily available?

Despite the unlikelihood that DNA synthesized commercially would be used for bioterrorism, we have adopted an effective procedure for ensuring that dangerous synthesized sequences do not fall into the wrong hands, a process that both GENEART and DNA2.0 currently implement with all their orders. On the basis of select agent lists from the US Centers for Disease Control and Prevention, the US Department of Agriculture (http://www.selectagents.gov/) and the Australia Group (http://www.australiagroup. net/), we have compiled a list of sequences against which we screen all incoming orders. We do not produce or ship genes that match any sequence on this list without an official permit ${ }^{8}$.

This protocol has several advantages over Nouri and Chyba's suggestions. It is effective immediately and does not have to await a distant future when gene synthesis is so perfectly automatable that punching a few keystrokes into a computer will pop out the Spanish flu virus. By screening against a list of restricted sequences within the company, rather than exposing sensitive or proprietary sequences to a transparent system, we can ensure that laboratories and researchers feel secure enough to utilize our services. If customers suspected that the confidentiality of their sequences might in any way be compromised, we would witness a withering of the enormous amount of innovation currently facilitated by synthesis; it could even compromise our ability to respond to potential pandemics 9 .

Although we stand behind our selfimposed regulation, there is no doubt that the government could act to improve its efficacy. For this reason, we call upon both the United States and Europe to require all makers of synthetic genes to screen according to a list of restricted sequences compiled by the relevant experts. We have done our best to craft a screening list, but we believe that our governments should be able to provide the most up-to-date and accurate list of restricted sequences.

Equally important to a comprehensive screening list is a plan for enforcement. We believe that our governments should routinely test all synthetic gene makers for compliance to the list. In this way, any irresponsible gene manufacturers can be immediately shut down. By routinely attempting to order dangerous sequences from laboratories outside of Europe and the United States, we can have an effective surveillance program even if we are not able to get international agreement on regulations such as proposed by the Australia Group. Whether through governmental channels or the world media, gene makers who act irresponsibly will not be able to continue to operate profitably. As we have seen recently in regards to food safety, international attention to contaminated food originating in China provoked an immediate shift in consumer behavior and, in turn, swift action by the Chinese government to crack down on irresponsible companies.

This is a time in our history when gene synthesis offers considerable assistance in tackling the mounting pressures of climate change, a burgeoning world population and pertinacious disease. Furthermore, gene synthesis provides scientists with valuable tools to find solutions to bioterror itself, facilitating the development of vaccines and diagnostic antibodies without requiring the culturing of active pathogens. By implementing a simple, sane regulation and enforcement policy regarding gene synthesis, 
we can head off the possibility that synthesized genes could be used to cause harm. We do not find any value in resorting to science fiction fantasies to foment fear about the process of gene synthesis. In our view, this endangers the very industry that will generate important solutions for our present problems while obscuring the true threats to our security.

\section{COMPETING INTERESTS STATEMENT}

The authors declare competing financial interests: details accompany the full-text HTML version of the paper at http://www.nature.com/naturebiotechnology/.

\section{Jeremy Minshull ${ }^{1} \&$ Ralf Wagner ${ }^{2}$ \\ ${ }^{1}$ DNA2.0, Inc, Menlo Park, California, USA. \\ ${ }^{2}$ GENEART, Regensburg, Germany. \\ e-mail:jminshull@dna20.com}

1. Nouri, A. \& Chyba, C.F. Nat. Biotechnol. 27, 234-236 (2009).

2. Czar, M.J., Anderson, J.C., Bader, J.S. \& Peccoud, J. Trends Biotechnol. 27, 63-72 (2009).

3. Hoover, D.M. \& Lubkowski, J. Nucleic Acids Res. 30, e43 (2002).

4. Xiong, A.S. et al. Nat. Protoc. 1, 791-797 (2006).

5. Reisinger, S.J., Patel, K.G. \& Santi, D.V. Nat. Protoc. 1, 2596-2603 (2006)

6. Cello, J., Paul, A.V. \& Wimmer, E. Science 297, 10161018 (2002).

7. FitzGerald, D. \& Pastan, I. J. Natl. Cancer Inst. $\mathbf{8 1}$ 1455-1463 (1989)

8. Bügl, H. et al. Nat. Biotechnol. 25, 627-629 (2007).

9. Song, L. et al. PLoS One 3, e2257 (2008).

\section{Chyba and Nouri reply:}

Concerns about the possible misuse of gene synthesis in particular and biotech more generally are not "science fiction fantasies," but rather a legitimate cause for concern. Attempts to address these concerns must be carefully balanced against the extremely important benefits that flow from these technologies, as we emphasize in the first paragraph of our Commentary ${ }^{1}$. The seriousness of the possible misuse of these technologies has been addressed by two National Academy of Sciences committees ${ }^{2,3}$, and in a workshop held by the Royal Society and the International Council for the Life Sciences ${ }^{4}$. (For full disclosure, one of us was a member of one of these Academy committees and a participant in the Royal Society workshop that led to the new report.)

Minshull and Wagner criticize our suggestions on three grounds: first, the "cat is already out of the bag" and "anyone who is sufficiently motivated" can already synthesize genes "or even an entire viral genome"; second, the requirement that legitimate users be able to readily bypass any controls will permit "hackers" to bypass these controls; and third, gene synthesis is "an unlikely tool for anyone considering harm" because there are so many other biological and conventional means to cause harm. We acknowledged these objections but did not find them sufficient to mean that nothing should be done.

What is striking is that, despite their rhetoric, Minshull and Wagner obviously agree with us on this. They themselves summarize the controls that their companies, and others, have placed on gene synthesis, based on the select agent lists. They require official permits for certain genes to be produced or shipped. Moreover, they call upon governments in the United States and Europe to "require all makers of synthetic genes to screen" synthesis orders. So, in fact, there is no disagreement in principle between their viewpoint and ours; the difference exists in the specifics of its application.

There is no silver bullet that will somehow solve the security challenge of dual-use biotech. Rather, we must implement a web of measures, carefully calibrated so as not to impede legitimate and lifesaving research, that will make it more challenging - not render impossible - the casual or even dedicated misuse of this technology. The hope is that such misuse will be challenging enough that any individual or group contemplating it will choose an altogether different approach to doing harm. But were the technology to become both extremely easy to use and widely available, further steps might be required to help ensure these favorable outcomes.
We do not suggest that gene synthesis companies drop their controls; in fact in our Commentary we applaud the steps that have been taken. Our concern, rather, lies with a possible future-whose trajectory can already be discerned-in which automated DNA synthesis machines diffuse to a large number of users. In this case, additional proposals beyond those applicable to central providers must be considered. Our suggestions, like those implemented by Minshull and Wagner, build on the select agent list and, like theirs, would require some permit structure for the synthesis of especially dangerous sequences which, like theirs, introduces some vulnerability to misuse that must be managed. In effect, we simply recommend extending their practices to a new technology. Given their call for greater government requirements along these lines for their own industry, we are puzzled why they object to our suggestions.

1. Nouri, A. \& Chyba, C.F. Nat. Biotechnol. 27, 234-236 (2009).

2. National Research Council. Biotechnology Research in an Age of Terrorism: Confronting the 'Dual Use' Dilemma (National Academies Press, Washington, DC, 2003).

3. Committee on Advances in Technology and the Prevention of their Application to Next Generation Biowarfare Threats. Globalization, Biosecurity, and the Future of the Life Sciences (National Academies Press, Washington, DC, 2006).

4. Science Policy Centre. New Approaches to Biological Risk Assessment (The Royal Society, London, 2009).

\section{Commercialized GM crops and yield}

\section{To the Editor:}

A News article in the July issue $e^{1}$ brings up some important questions about our report, Failure to Yield, which analyzes the contribution of genetic engineering to increased food and feed production in the United States, and its potential for contributing to global food security. I would like to clarify some points by responding to some of the comments made by several researchers interviewed in the article.

We do not recommend that genetic engineering be scrapped in favor of conventional breeding - the main complaint of Jonathan Jones. We note in the executive summary: "Genetic engineers are working on new genes that may raise both intrinsic and operational yield in the future, but their past track record for bringing new traits to market suggests caution in relying too heavily on their success" [emphasis added $]^{2}$. We should favor methods that have been, and continue to be, more successful at increasing productivity, such as conventional and genomicsassisted breeding - this does not mean eliminating genetic engineering.

Our report relied heavily (but not exclusively) on US field trials to derive yield values for genetically engineered traits. Field trials allow the comparison of crop treatments, while holding other variables relatively constant. This allows the testing of the yield contribution of a transgene-which was a goal of our report. Field trials are conducted under ambient 
environmental conditions-as would occur on farms. This is far from the "optimal conditions" that Wayne Parrott claims make these tests unrealistic. Field tests are not perfect-for instance, they may miss some important sporadic factors and may suffer from edge effects because of their small size. But they nevertheless provide a reasonable facsimile of farm conditions.

And genetic engineering certainly has not always been a last resort, as Parrott also contends. For example, a large amount of time, effort and money was devoted unsuccessfully to developing virus-resistant genetically modified (GM) sweet potatoes in Kenya, at the same time that conventional resistance was being developed ${ }^{3}$. More generally, agro-ecological methods often produce multiple benefits that may out-yield existing GM traits. The push-pull system for controlling both stem borer-the target of Bacillus thuringiensis toxin $(B t)$ corn in Africa-as well as striga, a serious parasitic weed, is one example ${ }^{4}$.

Val Giddings points out that the gap between intrinsic and operational yield may sometimes be smaller in the United States than in developing countries (but apparently not for GM soybeans in Argentina) ${ }^{5}$. But there are more technologies that influence yield in the United States that can be compared with the transgene-which provides a more rigorous test of the relative value of GM traits than on resource-poor farms, which have few technology options. Almost any inputs, such as fertilizers, can often substantially boost yield for resourcepoor farmers. The more important question is how well GM traits perform in comparison to other approaches, and at what cost. An important conclusion of our report is that genetic engineering has not performed nearly as well as other agricultural technologies in the United States for increasing yield. But broad comparisons have not often been done in developing countries. When such comparisons are made, we do not believe that genetic engineering will fare as well as other approaches.

Ken Ostlie remarks on the high efficacy of $B t$ against corn borer-a point that we agree with. But we do not believe that regional suppression of corn borer is likely to make much difference regarding the overall, aggregate yield impact of Bt corn in the United States. Most farmers who could derive a yield benefit are already using $B t$ corn, and this has been accounted for in our report. Regional borer suppression would not add much in terms of yield gain. A more likely benefit of regional suppression may be a reduced need to buy Bt corn seed.

Finally, Mike Gale notes that farmers are smart enough to know whether GM seed is providing benefits that are worth the extra cost. But our report focuses specifically on yield at the national level, not all possible benefits. Although it is only one of many crop characteristics, yield is a vitally important part of the equation of providing enough food for a growing global population, and therefore deserves our attention.

\section{Doug Gurian-Sherman}

Union of Concerned Scientists, Washington, DC, USA.

e-mail:dgurian-sherman@ucsusa.org

1. Sheridan, C. Nat. Biotechnol. 27, 588-589 (2009).

2. Gurian-Sherman, D. Failure to Yield: Evaluating the Performance of Genetically Engineered Crops (Union of Concerned Scientists, Cambridge, Massachusetts, USA; 2009) <http://www.ucsusa.org/assets/documents/ food_and_agriculture/failure-to-yield.pdf $>$.

3. Anonymous. New Scientist 181, 7 (7 February 2004) <http://www.newscientist.com/article/ mg18124330.700-monsanto-failure.html>

4. Khan, Z.R., Pickett, J.A., Wadhams, L.J., Hassanali, A. \& Midega, C.A.O. Crop Prot. 25, 989-995 (2006).

5. Qaim, M. \& Traxler, G. Agric. Econ. 32, 73-86 (2005).

\section{To the Editor:}

As a science-based publication you should make every effort to discuss data and opinions on all sides of a topic rather than serve as a vehicle for the promotion of one particular industry or interest group. A case in point is the report by Cormac Sheridan that appeared in your July issue ${ }^{1}$. This article is a discussion of a manuscript by Doug Gurian-Sherman at the Union of Concerned Scientists (Washington, DC) concluding that there has been little if any increase in crop yields with genetically modified (GM) food crops in the United States ${ }^{2}$. Although GurianSherman's conclusions were criticized, there was no mention of independently published data that supported his thesis. In addition, the news article interviewed several individuals directly associated with industry, but hid these ties under the guise of "publicsector crop scientists." Finally, there were a number of misleading statements.

With respect to the first point, the International Assessment of Agricultural Knowledge, Science and Technology for Development (IAASTD), a multiyear study commissioned by the United Nations (New York), concluded that "After a dozen years of commercial planting of GM crops, including maize, cotton, soybean and oilseed rape, there is no evidence of sustained, reliable or consistent increases in yield. In fact, there have been strong indications that the adoption of GM crops has resulted in yield declines"3. This study and popular media articles with similar conclusions ${ }^{4}$ are common knowledge, and should have been cited.

Second, and perhaps most egregiously, is the misrepresentation of the individuals quoted in the text as "public-sector crop scientists" when, in fact, they receive monetary compensation, directly or indirectly, from major plant biotech companies. For example, Jonathan Jones owns part of Mendel, a company whose website claims that a large amount of its output is purchased by the world's largest GM seed company, Monsanto (St. Louis), which also has first right of refusal for some of its product lines (http://www. mendelbio.com/aboutus/advisoryboard. php and http://www.mendelbio.com/ strategicpartners/index.php), whereas Kenneth Ostlie has received funding from Syngenta (Basel) and Pioneer Hi-Bred (Des Moines, IA, USA) (http://www. entomology.umn.edu/Faculty/ostlie/ ostlcv.htm). Finally, Wayne Parrott, who is frequently used by Nature Biotechnology as a source, is a scientific advisor of the International Life Sciences Institute (ILSI; Washington, DC; http://www.princeton. edu/morefoodlesscarbon/speakers/ wayne-parrott/). This organization is a lobby group that at least one source (http://www.sourcewatch.org/index. php?title=International_Life_Sciences_ Institute) claims has a hidden agenda to protect the interests of the food, chemical and drug industries. Among its sponsors are Monsanto and members of the tobacco industry. In 2006, the organization was banned from participating in World Health Organization (WHO; Geneva) activities after warnings from health, environmental and union groups_-including the Environmental Working Group (Washington, DC) and Natural Resources Defense Council (New York)—that WHO risked "scientific credibility and may be compromising public health by partnering with ILSI" (http://www.sourcewatch. org/index.php?title=International_ Life_Sciences_Institute). Therefore, it is disingenuous for these individuals to be represented as "public-sector crop scientists," and their industry ties should have been clearly stated in the main text.

Finally, the claim that "no one compels farmers in developing or developed countries to buy the generally more expensive biotech seed" is only partially true. In the United States, farmers that I have spoken with purchase seed from cooperatives where their 
choices are very limited, most likely because the big GM seed companies have purchased many of the independent producers ${ }^{5}$. Also, to get a decent price on required farm chemicals that are also sold by the GM seed companies, the farmers may have to purchase the GM seed even though the GM trait itself is useless to them. In addition, the purchase of GM seeds is sometimes a defensive measure because farmers know they can be put out of business by biotech companyinitiated lawsuits if their non-GM crops become contaminated by GM pollen from neighboring farms ${ }^{6}$. Finally, in developing countries the farmers frequently do not know what they are buying and they rely on local representatives who promote the latest, most expensive seeds that have not been properly tested for the area ${ }^{7}$. Third world officials have been known to take bribes from US companies ${ }^{8}$.

If Nature Biotechnology wants to represent itself as an unbiased advocate for technology, then it should ensure that its reporting covers all sides of an issue.

\section{David Schubert}

Salk Institute, La Jolla, California, USA. e-mail: schubert@salk.edu

1. Sheridan, C. Nat. Biotechnol. 27, 588-589 (2009).

2. Gurian-Sherman, D. Failure to Yield: Evaluating the Performance of Genetically Engineered Crops (Union of Concerned Scientists, Washington, DC, 2009) <http:// www.ucsusa.org/assets/documents/food_and_agriculture/failure-to-yield.pdf>. Accessed July 2009

3. Heinemann, J.A. Hope Not Hype: The Future of Agriculture Guided by the International Assessment of Agricultural Knowledge, Science and Technology for Development (Third World Network, Penang, Malaysia, 2009).

4. Begley, S. Feeding the 900 million: let them eat micronutrients. Newsweek 152, 53-54 (2008). $<$ http://newsweek.com/id/160075>.

5. Fernandez-Cornejo, J. et al. in The Seed Industry in U.S. Agriculture. Agriculture Information Bulletin Number 786 (Publishing Resource Economics Division, Economic Research Service, USDA, Washington, DC, 2004) p. 30-40 <http://www.ers.usda.gov/publications/aib786/aib786h.pdf>.

6. Kimbrell, A. \& Mendelson, J., eds. Monsanto vs. U.S. Farmers (Center for Food Safety, Washington, DC, 2005) <http://www.centerforfoodsafety.org/ Monsantovsusfarmersreport.cfm>.

7. Stone, G.D. Curr. Anthropol. 48, 67-103 (2007).

8. Anonymous. Monsanto fined $\$ 1.5 \mathrm{~m}$ for bribery. $B B C$ News, January 7, 2005 <http://news.bbc.co.uk/2/hi/ business/4153635.stm>.

\section{Nature Biotechnology replies:}

We agree with Schubert that the article's use of "public sector" as a descriptor for the crop scientists quoted in the piece was potentially misleading, given their ties to industry. Schubert also refers to the IAASTD report as support for the Gurian-Sherman manuscript. For this journal's analysis of IAASTD, the reader is referred to an editorial $^{1}$ and related correspondence ${ }^{2,3}$.
1. Anonymous. Nat. Biotechnol. 26, 247 (2008).

2. Heinemann, J.A. Nat. Biotechnol. 26, 499-500 (2008).

3. Chataway, J., Tait, J. \& Wield, D. Nat. Biotechnol. 26, 500-501 (2008).

\section{To the Editor:}

A News story in your July issue highlights a controversial report from the Union of Concerned Scientists concluding that commercialized genetically modified (GM) crops have had negligible effect on food crop yields in the United States ${ }^{1}$. Despite the increasing use of GM crops around the world ${ }^{2}$, agricultural biotech remains contentious in some countries, especially in Europe ${ }^{3}$. Influenced by biased reports, Europeans tend to overrate GM crop risks, while underrating the benefits ${ }^{4}$. Claims that the technology is needed to ensure food security and poverty reduction are often considered empty promises and are dismissed as industry propaganda. This in turn prompts widespread public concerns about negative social implications in developing countries ${ }^{5}$. Correspondence in this journal has also documented how GM crop opposition in Europe is hurting farmers and researchers ${ }^{6}$. More seriously, through trade relations and lobbying efforts of antibiotech groups, European attitudes are spilling over to developing countries, where they crucially impede biotech developments as well ${ }^{7}$. Here, we summarize our recent research on the socioeconomic effects of insect-resistant Bacillus thuringiensis toxin (Bt) cotton in India ${ }^{8,9}$. In this case, at least, there is strong evidence that the trait in this crop is already contributing to poverty reduction in the subcontinent.

$B t$ cotton containing the gene for the CrylAc protein was commercialized in India in 2002. Although only a few Bt cotton hybrids were initially available, their number has increased substantially to over 150 since 2004. Some of them also carry the gene for Cry2Ab. In 2008, around five million Indian small-scale farmers had adopted $B t$ technology, with an average cotton area of 1.5 ha. Many of them live below the poverty line. Several rounds of a representative farm survey reveal that $B t$-adopting farmers use $41 \%$ less pesticides and obtain $37 \%$ higher yields, resulting in an $89 \%$ gain in cotton profits on average ${ }^{8}$. In spite of seasonal and regional variation, these advantages have been sustainable over time. In monetary terms, mean profit gains are $\$ 135$ per ha. For the 7.6 million ha currently under $B t$ cotton in India, this means an additional $\$ 1$ billion in the hands of small-scale farmers. These are the technology's direct benefits.
Yet, there are also indirect benefits. For instance, higher cotton yields provide more employment opportunities for agricultural laborers and a boost to rural transport and trading businesses. Income gains among farmers and farm workers entail higher demand for food and nonfood items, inducing growth and household income increases also in other local sectors. Using a village modeling approach and taking into account such spillovers to other markets and sectors, we find that each hectare of Bt cotton creates aggregate incomes that are $\$ 246$ higher than those of conventional cotton (Fig. 1) ${ }^{9}$. For the total $B t$ cotton area in India, this translates into an annual rural income gain of $\$ 1.87$ billion. That is, each dollar of direct benefits is associated with over 80 cents of additional indirect benefits in the local economy.

In terms of income distribution, all types of households benefit, including those below the poverty line (Fig. 1). Sixty percent of the gains accrue to the extremely and moderately poor. $B t$ cotton also generates net employment, with interesting gender implications. Compared to conventional cotton, $B t$ increases aggregate returns to labor by $42 \%$, whereas the returns for hired female agricultural workers increase by $55 \%$ (ref. 9). This is largely due to additional labor employed for picking cotton, which is primarily a female activity in India. As is known, women's income has a particularly positive effect for child nutrition and welfare ${ }^{10}$.

Numerous studies show that sizeable direct benefits are also observed for other GM crop applications in developing countries (reviewed by M.Q. in ref. 4), although a comprehensive evaluation of indirect social effects remains

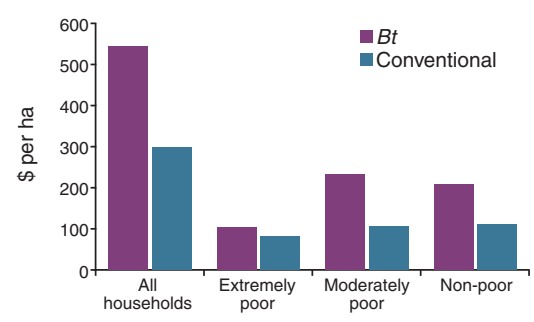

Figure 1 Household income effects of Bt cotton in comparison to conventional cotton in rural India. The results shown include direct benefits among cotton farmers as well as indirect effects through spillovers to other rural markets and sectors. For the evaluation of income distribution effects, households were disaggregated using local poverty lines, which are very near to the World Bank's thresholds of $\$ 1$ and $\$ 2$ a day (purchasing power parity) for extreme and moderate poverty, respectively (ref. 9). 
a clear priority. The results reported here cannot be simply extrapolated, as impacts always depend on the conditions in a particular setting. Nonetheless, the fact that a firstgeneration GM crop like Bt cotton already contributes to poverty reduction and rural welfare growth has not been widely recognized up till now and might further the public debate. Intelligent policies need to ensure that future biotech developments will also be pro-poor.

\section{ACKNOWLEDGMENTS}

The financial support of the German Research Foundation (DFG) is gratefully acknowledged.

Matin Qaim ${ }^{1}$, Arjunan Subramanian ${ }^{2}$ \& Prakash Sadashivappa ${ }^{3}$

${ }^{1}$ Georg-August University of Goettingen,

Department of Agricultural Economics and Rural
Development, Goettingen, Germany. ${ }^{2}$ University of Warwick, Coventry, UK. ${ }^{3}$ University of

Hohenheim, Stuttgart, Germany.

e-mail:mqaim@uni-goettingen.de

1. Sheridan, C. Nat. Biotechnol. 27, 588-589 (2009).

2. Marshall, A. Nat. Biotechnol. 27, 221 (2009).

3. Meldolesi, A. Nat. Biotechnol. 27, 304 (2009).

4. Qaim, M. Annu. Rev. Res. Econ. doi:10.1146/annurev. resource.050708.144203 (2009).

5. Sheridan, C. Nat. Biotechnol. 27, 9-10 (2009).

6. Rauschen, S. Nat. Biotechnol. 27, 318-319 (2009).

7. Paarlberg, R.L. Starved for Science: How Biotechnology is Being Kept Out of Africa (Harvard University Press, Cambridge, Massachusetts, 2008).

8. Sadashivappa, P. \& Qaim, M. AgBioForum (in the press).

9. Subramanian, A. \& Qaim, M. J. Dev. Stud. (in the press)

10. Quisumbing, A.R., Brown, L.R., Feldstein, H.S., Haddad, L. \& Peña, C. Women: The Key to Food Security (International Food Policy Research Institute, Washington, DC, 1995)

\section{The neonatal blood-brain barrier is functionally effective, and immaturity does not explain differential targeting of AAV9}

\begin{abstract}
To the Editor:
In the January issue, Foust et al. ${ }^{1}$ reported the interesting finding that adeno-associated virus (AAV) 9, when injected intravenously, targets different cell types in the brain in an age-dependent manner. When injected into neonatal mice (1 day old, P1), AAV9 was
\end{abstract} predominantly distributed in neurons, whereas in adult mice, it was mainly found in astrocytes. The authors make several unreferenced statements about the blood-brain barrier (BBB) in neonates- "not fully developed," "before the closure of the BBB" - and suggest that immaturity of the BBB accounts, at least in part, for the age-related difference in cellular uptake. The authors do not state what aspect of BBB mechanisms they consider not fully developed, although they mention in their Discussion that "Normally, tight junctions severely restrict penetration of the BBB by molecules and viruses." If this is the barrier mechanism that they have in mind, they are incorrect. Although it is widely stated that the $\mathrm{BBB}$ is immature or incompletely formed in neonates, the tight junctions between cerebral endothelial cells (the morphological basis for BBB impermeability) are functionally effective as soon as the first blood vessels penetrate the parenchyma of the developing brain ${ }^{2,3}$.

The evidence presented by Foust et al. shows that AAV9 penetrates the

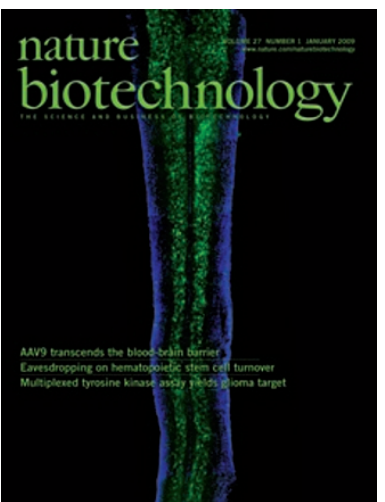
brain in both neonatal and adult mice. Thus, the state of BBB maturity is probably not relevant. It is much more likely that the predominance of AAV9 in neurons compared with astrocytes in neonatal brain is due to a different developmental phenomenon, namely, that there are relatively few astrocytes in neonatal brains, as pointed out by Lowenstein ${ }^{4}$ in his News \& Views, and that the astrocytic endfeet are not yet fully developed. Astrogenesis in rodents occurs in the early postnatal period. At the time of birth there are only occasional astrocytic endfeet associated with cerebral blood vessels, and the investment of blood vessels by astrocytic endfeet that is characteristic of the adult brain is not complete until 3 weeks of age ${ }^{5}$. Once these endfeet are in place, it may be that they trap much of the AAV9 entering the brain in the adult, thus preventing the widespread neuronal distribution seen in the neonates.

The common belief among neuroscientists that the BBB is 'immature' in the neonate seems to stem from the view that because a system is developing it is necessarily immature and from acceptance of evidence produced by experiments in which very large volumes of test materials have been injected, thereby damaging fragile blood vessels in the developing brain ${ }^{6-8}$. Therefore, it is of concern that Foust et al. state in their Methods section that "virus injections were in a total volume of $100 \mu \mathrm{l}$ of PBS." Given that newborn mice weigh 1-2 g, their total blood volume would be $<100-200 \mu l$. Intravenous injection of such a large proportion of the circulating blood volume would have a damaging effect even in adults, let alone on fragile blood vessels of the newborn ${ }^{7}$. In the context of normal physiological function, fragility does not equate with immaturity; rather, it describes a mechanical reaction when a physiological system is abused rather than being a manifestation of a developmental biological phenomenon. In the experiments of Foust et al., no controls were carried out to check on the integrity of the BBB. It would need to be clarified whether damage had occurred before the authors' explanation and our and Lowenstein's alternative explanation could be differentiated. The authors state that, in the adult, transduction was almost exclusively in astrocytes. There may be indirect effects on neurons via astrocytes with release, for example, of growth factors, but the proposal that AAV9 could facilitate gene therapy for adult diseases involving neurons, such as Parkinson's disease and Alzheimer's disease, seems premature on the basis of the evidence presented.

\section{Norman R Saunders, C Joakim Ek \& Katarzyna M Dziegielewska}

Department of Pharmacology, University of Melbourne, Parkville, Victoria, Australia. e-mail:N.Saunders@utas.edu.au

1. Foust, K.D. et al. Nat. Biotechnol. 27, 59-65 (2009).

2. Ek, C.J. et al. J. Comp. Neurol. 460, 451-464 (2003).

3. Ek, C.J. et al. J. Comp. Neurol. 496, 13-26 (2006).

4. Lowenstein, P.R. Nat. Biotechnol. 27, 42-44 (2009).

5. Caley, W.D. \& Maxwell, D.S. J. Comp. Neurol. 138 31-48 (1970)

6. Saunders, N.R. et al. in Developmental Neurotoxicology (eds. Harry, J. \& Tilson, H.) (Informa Health Care, New York, 2009).

7. Saunders, N.R. Handbook Exper. Pharmacol. 103 327-369 (1992).

8. Saunders, N.R. et al. Trends Neurosci. 31, 279-286 (2008). 
Foust, Chicoine and Kaspar reply: We thank Saunders et al. for their letter and thoughtful comments regarding our paper ${ }^{1}$ and the News \& Views by Lowenstein ${ }^{2}$. The authors raise the correct point that tight junctions between cerebral endothelial cells are functional in the developing brain, whereas the intimate associations of astrocytic endfeet are not complete until at least 3 weeks of age $^{3}$. Our representation of this point in our paper could have been more clearly stated. Indeed, our reported results are consistent with the interpretation that AAV9 injected intravenously can bypass endothelial cells, probably through transcytosis mechanisms, in both the neonate and the adult. We found that in the neonate, the virus is capable of readily transducing neurons throughout the brain, whereas in the adult, it can transduce only the polar astrocytic endfeet. Although the mechanistic basis of this differential transduction remains to be determined, it is interesting that our direct, intraparenchymal injections into the brain of adults resulted in little to no astrocytic transduction $^{1}$, suggesting that AAV9 requires entry through distinct receptors on the perivascular endfeet not accessible by the parenchymal route of delivery.

The authors' concern that the $100 \mu \mathrm{l}$ volume injected in the neonates could cause vascular damage is valid ${ }^{4}$. However, we did not observe any increase in mortality or morbidity in the reported experiments ${ }^{1}$ or in subsequent, unreported studies on over 50 neonatal animals. Animals maintained their normal behavior after injections, as assessed by daily observation as well as by motor function evaluation, which may have revealed motor cortex or spinal cord damage. Furthermore, we did not detect any pathological insults that might have indicated vascular damage in any of the brain or spinal cord sections examined.

Although we were confident that AAV9 was safely delivered, we subsequently performed additional studies with a smaller injection volume. Using similar viral titers, we injected $30 \mu \mathrm{l}$ of virus into neonatal animals and observed identical results as with the larger volume (Fig. 1). GFP was expressed in dorsal root ganglion (DRG), motor neurons and some astrocytes within the spinal cord, as well as neurons within the brain. Clinically, hemodynamically compromised term and

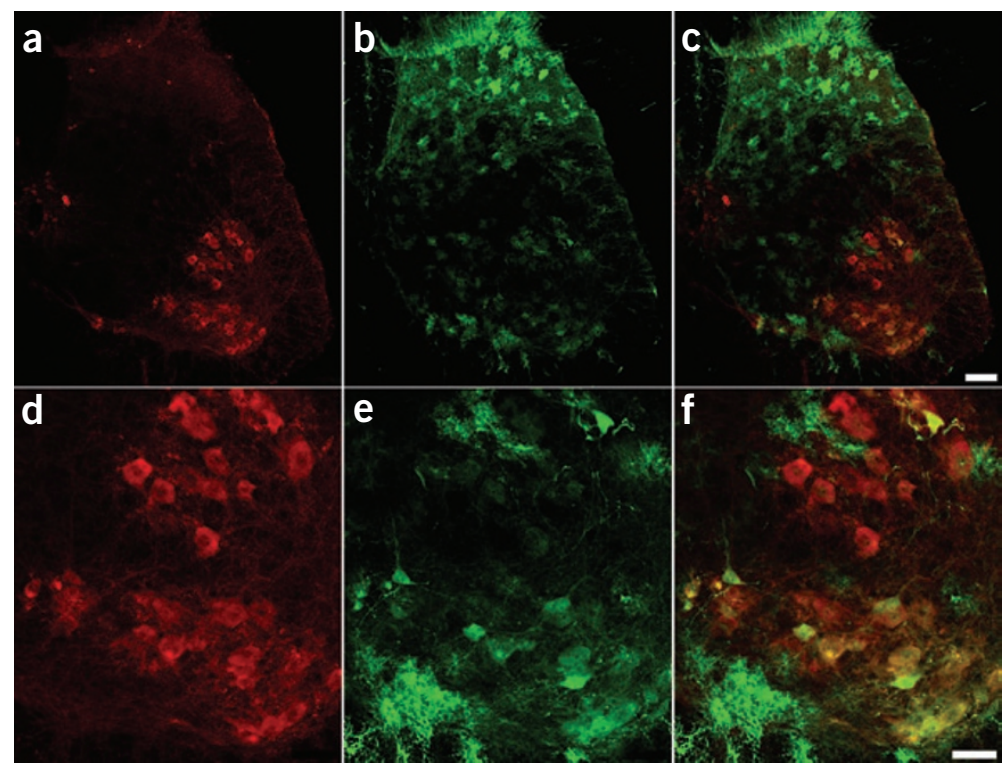

Figure 1 Intravenous injection of $1 \times 10^{11}$ particles of scAAV9 CB GFP in a total volume of $30 \mu \mathrm{l}$ to postnatal day 1 mice results in a similar pattern of gene expression within the spinal cord as in mice injected with $100 \mu \mathrm{l}$. (a-c) Low-power magnification of cervical spinal cord sections labeled for choline acetyl transferase (ChAT, a) or green fluorescent protein (GFP, b) show a similar pattern of dorsal root ganglia and lower motor neuron transduction (merged, $\mathbf{c}$ ) as in previously published results ${ }^{1}$. (d-f) A $z$-stack image from the same section of spinal cord shown in a-c demonstrates extensive colocalization of the ChAT (d) and GFP (e) signals (f, merged). Scale bars: c, $100 \mu \mathrm{m} ; \mathbf{f}, 50 \mu \mathrm{m}$.

preterm infants may be treated with similar volumes on a cc per kg basis, and repeated doses may push the volumes administered well above $30 \mathrm{cc} / \mathrm{kg}$. This clinical practice is equivalent to a $30 \mu \mathrm{l}$ injection in a $1 \mathrm{~g}$ mouse. As further indication that AAV9 is capable of crossing endothelial barriers, we did see transport through the endothelial cells after injections into the adult ${ }^{1}$, where the injected volume is of less concern. Astrocytes were primarily targeted with few to no neurons transduced ${ }^{1}$, indicating that our injections in adult animals did not damage the endothelial barrier or the perivascular astrocyte endfeet barrier. These results suggest that AAV9 has the ability to bypass tight endothelial cell barriers, probably through transcytosis, in both neonate and adult animals. Although these findings are certainly not conclusive, on the basis of our current data, we do not believe that 100 or $30 \mu \mathrm{l}$ injections cause substantial damage to the blood vessels in the newborn. Further direct studies with dye infusions following virus injection would be useful.

The final point raised in the authors' letter is that intravascular AAV9 delivery in adults may not be relevant to therapeutic development for Parkinson's, Alzheimer's and other adult-onset neurodegenerative diseases, given that the virus primarily targets astrocytes. It is becoming increasingly clear, however, that aberrant glial cell toxicity is partially responsible for neurotoxicity in Parkinson's disease ${ }^{5}$ and other neurodegenerative diseases ${ }^{6}$, and that targeting of astrocytes - the most abundant cell type in the brain-may be useful even for diseases in which astrocytes have no recognized dysfunction. Moreover, astrocytes may be very useful for generating biological pumps of trophic support factors for neurons given that they are intimately connected to vasculature and neurons throughout the entire brain. Finally, molecular-engineering techniques, such as evolving the viral capsid to bypass endothelial cells and astrocytic endfeet, might be used to achieve widespread neuronal targeting in adults by vascular delivery.

1. Foust, K.D. et al. Nat. Biotechnol. 27, 59-65 (2009), 2. Lowenstein, P.R. Nat. Biotechnol. 27, 42-44 (2009).

3. Caley, D.W. \& Maxwell, D.S. J. Comp. Neurol. 138 31-47 (1970).

4. Saunders, N.R., Ek, C.J., Habgood, M.D. \& Dziegielewska, K.M. Trends Neurosci. 31, 279-286 (2008).

5. Saijo, K. et al. Cell 137, 47-59 (2009).

6. Dodge, J.C. et al. Mol. Ther. 16, 1056-1064 (2008). 


\section{Corrigendum: Microdroplet-based PCR enrichment for large-scale targeted sequencing}

Ryan Tewhey, Jason B Warner, Masakazu Nakano, Brian Libby, Martina Medkova, Patricia H David, Steve K Kotsopoulos, Michael L Samuels, J Brian Hutchison, Jonathan W Larson, Eric J Topol, Michael P Weiner, Olivier Harismendy, Jeff Olson, Darren R Link \& Kelly A Frazer Nat. Biotechnol. 27, 1025-1031 (2009); published online 1 November 2009; corrected after print 11 November 2009

In the version of this article initially published, the email address for K.A.F. should have been kafrazer@ucsd.edu. The error has been corrected in the HTML and PDF versions of the article.

\section{Corrigendum: The valuation high ground}

Jeffrey J Stewart \& Ben Bonifant

Nat. Biotechnol. 27, 980-983 (2009); published online 24 September 2009; corrected online 6 November 2009; pdf corrected 5 February 2010

In the version of this article initially published, the email address for Ben Bonifant was incorrect. The email address is bbonifant@campbellalliance. com. The error has been corrected in the HTML and PDF versions of the article.

\section{Corrigendum: Receptor-binding specificity of pandemic influenza A (H1N1) 2009 virus determined by carbohydrate microarray}

Robert A Childs, Angelina S Palma, Steve Wharton, Tatyana Matrosovich, Yan Liu, Wengang Chai, Maria A Campanero-Rhodes, Yibing Zhang, Markus Eickmann, Makoto Kiso, Alan Hay, Mikhail Matrosovich \& Ten Feizi

Nat. Biotechnol. 27, 797-799 (2009); published online 9 September 2009; corrected after print 5 February 2010

In the version of this article initially published, two acknowledgments were inadvertently omitted: NCI Alliance of Glycobiologists for Detection of Cancer and Cancer Risk; and Biotechnology and Biological Sciences Research Council. The error has been corrected in the HTML and PDF versions of the article.

\section{Corrigendum: Small but not simple}

Markus Elsner

Nat. Biotechnol. 28, 42 (2010); published online 8 January 2010; corrected after print 5 February 2010

In the version of this article initially published, the organisms in question were incorrectly identified as Mycobacterium pneumoniae and Mycobacterium genitalium. The correct names are Mycoplasma pneumoniae and Mycoplasma genitalium, respectively. The error has been corrected in the HTML and PDF versions of the article.

\section{Erratum: A nuclear magnetic resonance technique for determining hybridoma cell concentration in hollow fiber bioreactors}

Anthony Mancuso, Erik J. Fernandez, Harvey W. Blanch \& Douglas S. Clark

Biotechnology 8, 1282-1285 (1990); corrected online 5 February 2010

In the version of this article initially published online, a graph published in print as Figure 2 was erroneously duplicated and appeared as both Figure 1 and Figure 2. The original Figure 1 has been restored in the online PDF version of the article.

\section{Erratum: Can web 2.0 reboot clinical trials?}

Malorye Allison

Nat. Biotechnol. 27, 895-902 (2009); published online 8 October 2009; corrected after print 5 February 2010

In the version of this article initially published, Sharib Khan was incorrectly identified as the CEO of TrialX. He is cofounder. The error has been corrected in the HTML and PDF versions of the article. 